\title{
多重連結車両の後退運動制御*
}

\author{
景山一 郎**, 斉藤安***

\section{Control of Multi-Articulated Vehicles in a Backward Maneuver}

\author{
Ichiro KAGEYAMA and Yasushi SAITO
}

\begin{abstract}
This paper describes the control of multi-articulated vehicles in a backward maneuver, which have been almost ignored to date. First, the equations of multi-articulated vehicle motion in a backward maneuver were obtained by the geometrical method. By experiment, it was found that their behavior at a low speed could be treated geometrically. Next, the controllability of articulated vehicles in this maneuver were studied theoretically with modern control methods. With the optimal control theory, the steering of these maneuvers was studied. These analyses provided the feed-back coefficients of each state value of multi-articulated vehicles and also the effects of design parameters for these coefficients. Finally, the control limit was studied with the limit value of steering angle.
\end{abstract}

Key Words : Transport Vehicles, Application of Control, Articulated Vehicles, Backward Maneuver, Optimal Control

\section{1. え がき}

連結車両の運動上の問題点としては，高速時におけ る安定性, 中低速時における追従性，制動時における ジャックナイフィング, おょび後退時における操作性 などがあげられる。これら連結車両固有の問題に対す る研究は数多く行われているが，これらは主に高速時 の安定性 ${ }^{(4)(5)}$, 中低速時の追彷性 ${ }^{(3)(5)}$, 制動時の安定 性 ${ }^{(6)} に$ 対するものであり，後退運動に関する研究はほ とんど行われていないのが実情である。しかし駐車場 などにおける後退時の操縦は運転者の熟練度合に大き く左右され，椿内などで使用されている多重連結車両 においては不可能に近いものと従来考光られてきた。

本研究では多重連結車両の後退運動を明らかにする ため，一般的後退理論の確立とその操縦に関する可制 御性，および最適制御による各状態量のフィードバッ ク係数について検討を行った．またけん引車の舵角に 限界があることから，制御限界についての検討も合わ せて行った。

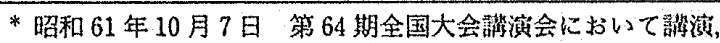
原稿受付 昭和 61 年 4 月 4 日.

** 正員, 日本大学生主工学部（275 習志野市泉町 1-2-1).

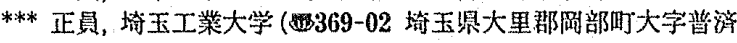
寺 1690).
}

\section{2. 多電連結車両の後退理論}

$2 \cdot 1$ 後退理論 低速走行時には車雨の夕イヤは ほとんど横すべりを発生せず，したがってその軌跡は 幾何学的に求めることができる(3)。そこで低速後退時 に动いても同様と考え，多重連結車両の運動を幾何学 的に取扱った。

計算モデルは図 1 に示すように,いわゆる「バイサ イクルモデル」と考え, 操舵角を庄右輸平均值として 扱う。また幾何学的な扱いではその軌跡を後退距離の 関数と考えることができ，本研究ではけん引車後輸の 後退距離を独立变数とした。

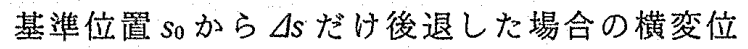
$y\left(s_{0}+\Delta s\right)$ および姿汾角 $\theta\left(s_{0}+\Delta s\right)$ は, 次式により示 さ机る。

$$
\begin{aligned}
& y\left(s_{0}+\Delta s\right)=y\left(s_{0}\right)+\Delta s \sin \theta \\
& \theta\left(s_{0}+\Delta s\right)=\theta\left(s_{0}\right)+\Delta s / R_{1}
\end{aligned}
$$

そこでその変化率を求めると次式のようになる。

$$
\begin{aligned}
& \frac{d y}{d s}=\sin \theta \ldots . \\
& \frac{d \theta}{d s}=\frac{1}{l_{1}} \tan \delta
\end{aligned}
$$

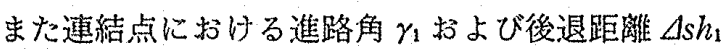


は次式で与えられる。

$$
\begin{aligned}
& \gamma_{1}=\tan ^{-1}\left(l_{h 1} / l_{1} \cdot \tan \delta\right) \\
& \Delta s_{h 1}=\Delta s / \cos \gamma_{1} \quad \ldots \ldots . .
\end{aligned}
$$

第 2 車両についても第 1 車両同槏に洘えると，姿勢 角変化率は次式で与えら机る。

$$
\frac{d \theta_{2}}{d s_{2}}=\frac{1}{l_{2}} \tan \left(\phi_{1}-\gamma_{1}\right)
$$

ここで第 1 車両と第 2 車両の連結点における後退距 離が等しいことから，次式の関係が得られる。

$$
\Delta s_{2}=\Delta s \cos \left(\phi_{1}-\gamma_{1}\right) / \cos \gamma_{1}
$$

ここで式（8)を式(7)に代入し，また $\theta_{2}=\theta+\phi_{1}$ の 関係を入れて整理すると次式が得られる。

$$
\frac{d \phi_{1}}{d s}=\frac{1}{l_{2}} \cdot \frac{\cos \left(\phi_{1}-\gamma_{1}\right)}{\cos \gamma_{1}} \tan \left(\phi_{1}-\gamma_{1}\right)-\frac{1}{l_{1}} \tan \delta
$$

これを第 $i$ 車両まで拡張すると次式が得られる。

$$
\begin{gathered}
\frac{d \phi_{i-1}}{d s}=\frac{\cos \left(\phi_{i-1}-\gamma_{i-1}\right) \cdots \cdots \cdot \cos \left(\phi_{1}-\gamma_{1}\right)}{l_{i} \cos \left(\gamma_{i-1}\right) \cdots \cdots \cos \gamma_{1}} \\
\quad \times \tan \left(\phi_{i-1}-\gamma_{i-1}\right)-\left\{\sum_{k=1}^{i-2} \frac{d \phi_{k}}{d s}+\frac{d \theta_{1}}{d s}\right\} \cdots \cdots \\
\gamma_{i-1}=\tan ^{-1}\left\{\frac{l_{h i-1}}{l_{i-1}} \tan \left(\phi_{i-2}-\gamma_{i-2}\right)\right\} \cdots \cdots \cdots
\end{gathered}
$$$$
\text { ここで } s^{*}=s / l_{1}, y^{*}=y / l_{1}, n_{j}=l_{j} / l_{1}, n_{h j}=l_{h_{j}} / l_{1} \text { のよ }
$$

うに，けん引車のホイルベースで各諸元を無次元化し て示すと, 式(3)〜 (5)，(10)，(11)は次のように示 される。(ただし $j=1 〜 i)$

$$
\begin{aligned}
& \frac{d y^{*}}{d s^{*}}=\sin \theta \\
& \frac{d \theta}{d s^{*}}=\tan \delta \\
& \frac{d \phi_{i-1}}{d s^{*}}=\frac{\cos \left(\phi_{i-1}-\gamma_{i-1}\right) \cdots \cos \left(\phi_{1}-\gamma_{1}\right)}{n_{i} \cos \gamma_{i-1} \cdots \cdots \cdot \cos \gamma_{1}} \\
& \quad \times \tan \left(\phi_{i-1}-\gamma_{i-1}\right)-\left\{\sum_{k=1}^{i-2} \frac{d \phi_{k}}{d s^{*}}+\frac{d \theta}{d s^{*}}\right\}
\end{aligned}
$$

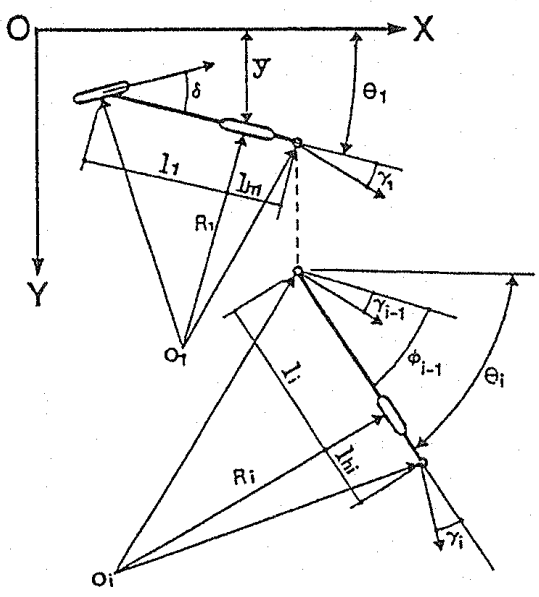

図 1 計算モデル

$$
\begin{aligned}
& \gamma_{1}=\tan ^{-1}\left(n_{h 1} \tan \delta\right) \ldots \ldots \ldots \ldots \ldots \ldots \ldots \ldots \ldots \ldots \\
& \gamma_{i-1}=\tan ^{-1}\left\{\frac{n_{h i-1}}{n_{i-1}} \tan \left(\phi_{i-2}-\gamma_{i-2}\right)\right\}
\end{aligned}
$$

$2 \cdot 2$ 本理論式の実車による確認 本研究で導い た理論を，栗用車・トレーラ系の笑験結果と対此を行 った。実験は，最大舵角に固定し各初期条件を零とし て後退運動を行った。

図 2 に示すように，理論と実験は非常に良い一致を みせこの理論の妥当性が亭付けされた。

$2 \cdot 3$ 線形化 直進後退, 車線乘移りなどの各角 度が微小な領域ではその後退運動を線形化することが できる。そこで式(12)，(13)，(14)を線形化しまとめる と，次の状態方程式が得られる。

$$
\frac{d X}{d s^{*}}=A X+B u
$$

ここで $\boldsymbol{X}$ は状態べクトル， $\boldsymbol{A}$ は系行列， $\boldsymbol{B}$ は制御 行列, $u$ は入力を示す. 状態量は $x_{1}=y^{*}, x_{2}=\theta, x_{3}=$ $\phi_{1}, x_{i+1}=\phi_{i-1}$ であり，式中の $A, B$ は次のように示さ れる。

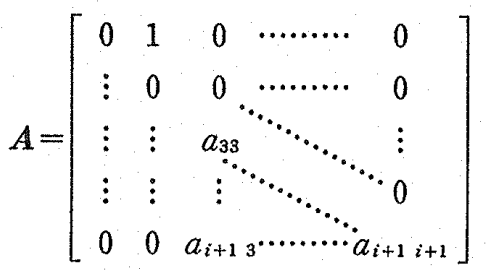
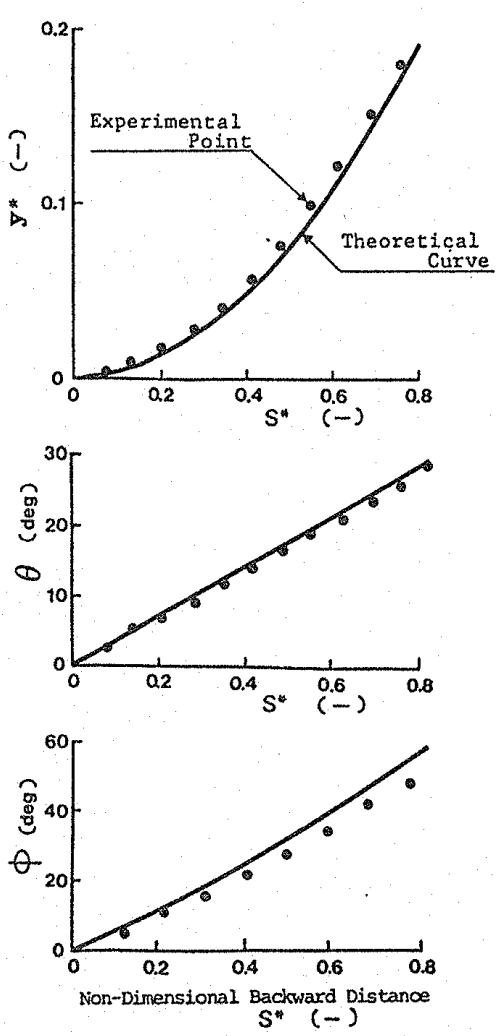

図 2 理論結果と実験結果の対応 


$$
B^{T}=\left[\begin{array}{llll}
0 & 1 & b_{3} & \cdots \cdots \cdots \\
b_{i+1}
\end{array}\right]
$$

ここで $j=3 \sim i+1, k=1 \sim j-3, j-l>2$ とすると, 各要素は次式で与えられる。

$$
\begin{aligned}
& a_{j j}=\frac{1}{n_{j-1}} \\
& a_{j j-k}=(-1)^{k} \frac{\prod_{l=3}^{k+1} n_{h j-l}}{\prod_{m=2}^{k+1} n_{j-m}}\left(1+\frac{n_{h j-2}}{n_{j-1}}\right) \\
& b_{j}=(-1)^{j} \frac{\prod_{l=1}^{j-3} n_{h l}}{\prod_{m=2}^{j-2} n_{m}}\left(1+\frac{n_{h j-2}}{n_{j-1}}\right)
\end{aligned}
$$

\section{3. 可 制御性}

式(11)で示した状態方程式を用い，多重連結車両の 後還運動の可制御性について検討を行う。

$i$ 両連結の可制御性は, 次式で示される合成行列 $G$ により確認され，この $G$ が正則であれば可制卸とな る.

$$
G=\left[B A B A^{2} B \cdots \cdots \cdot A^{i} B\right]
$$

この行列式を求めると次式となる。

$\operatorname{det} G=(-1)^{k} \frac{\left(n_{h 1}+n_{2}\right)\left(n_{h 1}+n_{3}\right) \cdots\left(n_{h 1}+n_{i}\right)}{n_{2}^{i+1} \cdot n_{3}^{i+1} \cdots \cdots \cdots \cdot n_{i}^{i+1}}$

$$
\left(n_{h 2}+n_{3}\right) \cdots \cdots\left(n_{k i-1}+n_{i}\right)
$$

$$
\text { だだし } i \text { が奇数のとき } k=(i-1) / 2+1
$$$$
i \text { が偶数のとき } k=i / 2+1
$$

そこで各車両の連結位置が次に示す条件であると， この多重連結車両は可制御となる。

$$
\left.\begin{array}{l}
n_{h 1} \neq-n_{2},-n_{3},-n_{4}, \cdots \cdots,-n_{i} \\
n_{h 2} \neq-n_{3},-n_{4}, \cdots \cdots \cdots,-n_{i} \\
\vdots \\
n_{h i-1} \neq-n_{i}
\end{array}\right\}
$$

\section{4. 後退運動 制 御}

$4 \cdot 1$ 解析理論 多重連結車両の後退時の操緹を 全状態量のフィードバックにより考える。また，通常 直進後退や車線乗移りなどではそれほど大きな姿㳺角 を持たないものと考えられ，式(17)で示した線形状態 方程式を用い解析を行う。

後退運動開始点から $s^{*}$ だけ後退した場合, 次の評 価関数を最小にするように操綻するものとする。

$$
J=\int_{0}^{s^{*}}\left(\boldsymbol{X}^{T} Q \boldsymbol{X}+u^{2}\right) d s^{*}
$$

ここでQは各状態量の重加係数を裂素とする対角 マトリックスであり，またいには制限がなく状態墨 のフィードバックにより決定されるものとして次式で 与える。
$u=-K^{T} X$

式(24)を式(17)，(23)k代入し，Hamilton-Jacobi の方法に適用すると最適制御 $u^{0}$ は次式で与えられ る。

$u^{0}=-\boldsymbol{B}^{T} \boldsymbol{R}\left(s^{*}\right) X$

ここで $s^{*}$ を考えると $\mathbb{R}\left(s^{*}\right)$ は定数となり，次の Riccati 式により与えられる。

$A^{T} R+R A-R B B^{T} R+Q=0$

そこでフィードバック係数は次式で与えられる。

$$
K=R B
$$

$4 \cdot 2$ 評価関数の決定 最適制御を考える場合, その評価関数の決定は非常に重要となる。そこで式 （23）で示した各状態量の重み係数の決定には，熟練し た運転者の後退車線乗移りの実験結果を用いた。図 3 に乗用車・トレーラ系の横変位の奏験結果および $q_{1}=$ $q_{2}=q_{3}=1$ の計算結果を示す。図 3 中の実験結果は十 分に練習を行った後に計測した 5 回の結果の領域を示 し，計算結果はこれに適合するように諸係数を決定し たものである。そこで解析に用いる諸係数はこれを抎 張し， $q_{k}=1.0$ とした。ただし $k=1 \sim i+1$ とする。

$4 \cdot 3$ 最適フィードバック係数 式(23)の評価関 数を最小にするようなフィードバック係数を式(27)よ り求めることができる。そこでこのフィードバック係 数を用い, 連結車両数の影響と各車両諸元変化による 影響を検討する。

表 1 は同一譛元を持つ車両 $\left(n_{k}=1, n_{h k}=0.6\right)$ を 2 5 両まで連結した場合の各状態量のフィードバッ ク係数を示したものである。連結数が偶数時に各係数 は負の値となっているが，これは運動方向と操舵方向 との関係によるものでありここではその絶対值に注 目する。

表 1 連結数と最適フィードバック係数

\begin{tabular}{|c|c|c|c|c|c|c|}
\hline$i$ & $y^{*}$ & $\theta$ & $\phi_{1}$ & $\phi_{2}$ & $\phi_{2}$ & $\phi_{4}$ \\
\hline 2 & -1.00 & -3.90 & -5.08 & - & - & - \\
\hline 3 & 1.00 & 5.99 & 3.70 & 6.61 & - & - \\
\hline 4 & -0.98 & -7.88 & -8.97 & -2.91 & -8.34 & - \\
\hline 5 & 1.00 & 10.11 & 7.85 & 10.71 & 1.74 & 10.75 \\
\hline
\end{tabular}

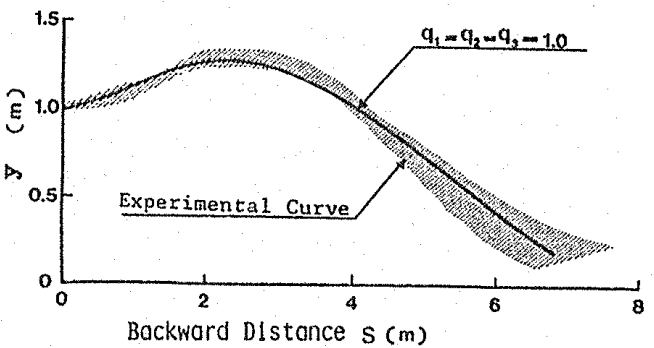

図 3 部価䦎数の決定 
連結数の変化に対し， $y^{*}$ のフードバック係数の 絶対值はほほ一定となっているが，，の係数は連結数 の增加に伴い増大していることがわかる。また最後端 の相対ヨ一角の係数は連結数の增加に伴って增大し， その絶刘値は他の係数と比較してほほ最大の值を示し ている、このように操縦者から最も蒸い位䈯にある車 両の状態量を操舵に対し最も大きく反映させなければ ならず，連結数の增加により後退操作が非常に国難と なることが璸付けられる。

次に 5 両連結時の各諸元変化に対するフィードバッ ク係数の変化率を表 2 に示す。各車両の諸元変化は, それ以後の車両の係数に対し大きく影響を与えること がわかる。また各諸元值の変化により最後端の相対ヨ 一角の係数が最も大きな影響を受け（最後端車両の木
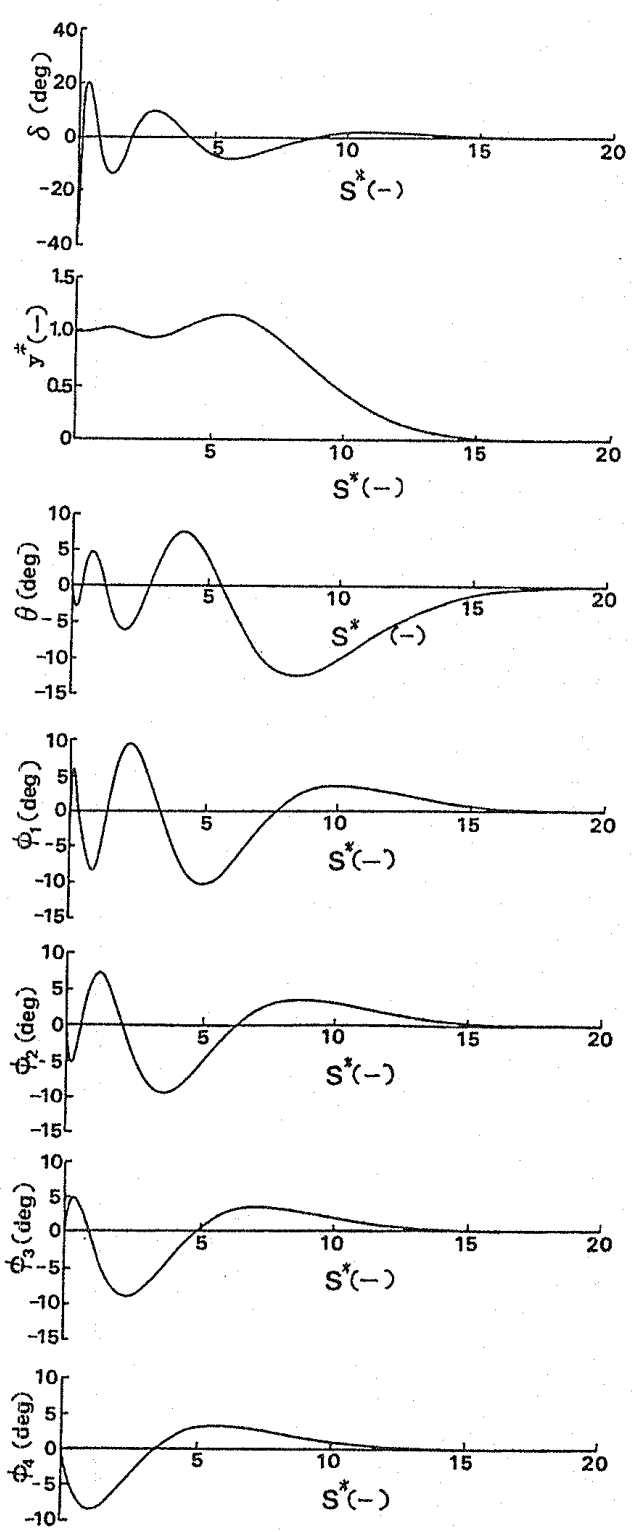

図 4 最適後退制御
イールベース変化を除く)，採縦者の負担を大きいも のとしていることがわかる。

$4 \cdot 4$ 最適後退制御 $4 \cdot 3$ 節に扔いて最適フィ一 ドバック係数を示したが，初期条件が若干大きくなる と，大力の值が增大し操舵角の限界に達してしまう。 しかし状態䊆はそれほど大きくならず，線形域で考え ることができる。このような場合，次の条件で入力を 考える。

$$
\begin{aligned}
& \left|u^{0}\right| \geqq\left|u_{\max }\right| \cdots \cdots u=u_{\max } \\
& \left|u^{0}\right|<\left|u_{\max }\right| \cdots \cdots u=u^{0}
\end{aligned}
$$

このように $U$ に制限がある場合でも前述の解析を 拡張することができる.そこで $4 \cdot 3$ 節で示した車両諸 元（5兩連結）について計算した結果を図 4 に示す. また 計算した。計算に使用した初期条件は，車線幅 1 (けん 引車のホイールベースと同值）の車線変更を表すもの である、図 4 に示されるように，一般的には不可能と 考えられる 5 両連結車両の後退制御が可能であること がわかる。

\section{5. 制 御 限界}

4 章までに後退運動制御を示したが，实際には操舵 角に限界があり，線形領域では可制御な系であっても 制御ができない場合が生ずる。図 5 に示す連結車は， 相対ヨ一角を減少するように操䊉を行い後退している が, 相対ヨー角の值に応じ 3 種類の挙動を示す。この 場合相対ヨー角が減少するものが制御可能で，増加す

表 2 諸元変化に対するフィードバック係数変化率

\begin{tabular}{|c|c|c|c|c|c|c|}
\hline & $y^{*}$ & $\theta$ & $\phi_{1}$ & $\phi_{2}$ & $\phi_{3}$ & $\phi_{1}$ \\
\hline$K$ & 1.00 & 10.11 & 7.85 & 10.71 & 1.74 & 10.75 \\
\hline$\frac{\partial K}{\partial n_{2}}$ & -0.04 & 1.54 & 1.65 & 3.41 & -3.04 & 4.80 \\
\hline$\frac{\partial K}{\partial n_{3}}$ & 0.02 & 2.14 & 2.10 & 2.10 & -3.24 & 5.19 \\
\hline$\frac{\partial K}{\partial n_{4}}$ & 0.04 & 2.35 & 2.39 & 2.39 & 2.32 & 5.32 \\
\hline$\frac{\partial K}{\partial A_{6}}$ & 0.01 & 2.18 & 2.23 & 2.15 & 2.25 & -0.43 \\
\hline$\frac{\partial K}{\partial n_{n 1}}$ & -0.04 & -0.16 & 1.57 & -5.50 & 4.84 & -5.48 \\
\hline$\frac{\partial \mathrm{K}}{\partial n_{n_{2}}}$ & 0.08 & 1.02 & 1.12 & -4.72 & 5.90 & -5.93 \\
\hline$\frac{\partial K}{\partial n_{n_{2}}}$ & 0.06 & 0.84 & 0.83 & 0.72 & 6.09 & -6.26 \\
\hline$\frac{\partial K}{\partial n_{n_{4}}}$ & -0.02 & -0.27 & -0.33 & -0.23 & -0.23 & -6.51 \\
\hline
\end{tabular}

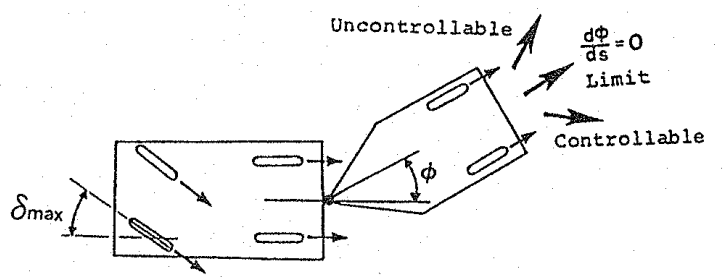

図 5 後退制御性 


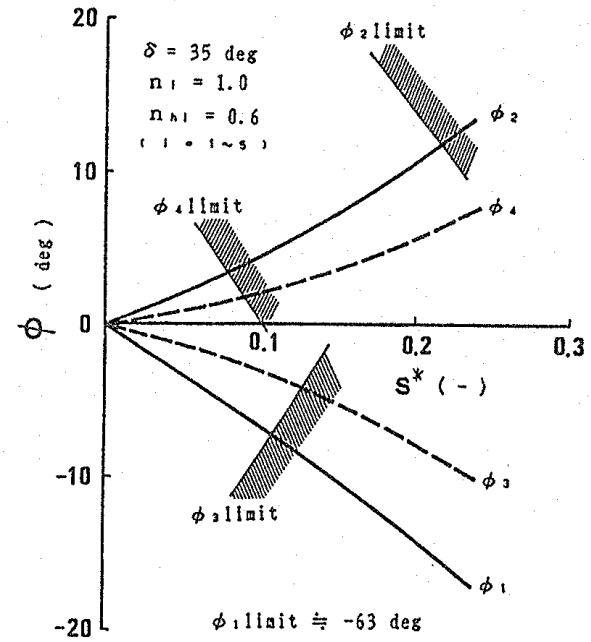

図 6 後退制御限界

るものが制御不可能，またその相対ヨ一角を維持する もの $\left(d \phi / d s^{*}=0\right)$ が限界となる。そこで 2 両連結の場 合の制御限界相対ヨー角を求めると次式となる。

$$
\begin{aligned}
& \phi_{1_{\text {HIMt }}}=\sin ^{-1}\left(\frac{n_{2}}{n_{h 1}} \sin \gamma_{1}\right)+\gamma_{1} \\
& \gamma_{1}=\tan ^{-1}\left(n_{h 1} \tan \delta_{\max }\right) \ldots \ldots .
\end{aligned}
$$

式(28)，(29)より明らかなように，2両連結の場合各 車两諸元と $\delta_{\max }$ により限界相対ヨ一角が決まる。同様 にして $i$ 両連結の第 $i-1$ と第 $i$ 両間の相対ヨ一角の 限锶值を求めると，次式により与えられる。

$$
\begin{aligned}
& \phi_{i-1_{\text {IIIIt }}}=\sin ^{-1}\left\{\frac{n_{i}}{n_{h i-1}} \sin \gamma_{i-1}\right\}+\gamma_{i-1} \\
& \gamma_{i-1}=\tan ^{-1}\left\{\frac{n_{h i-1}}{n_{i-1}} \tan \left(\phi_{i-2}-\gamma_{i-2}\right)\right\}
\end{aligned}
$$

この式より明らかなように，第 $i$ 車両の制御限界は 第 $i-1$ 車両までの状態量により与えられることにな
り，運動状態によりその限界值が異なる。そこで 4 章 で用いた 5 両連結で, 初期条件をすべて零とし，最大 舵角で後退した場合の各相対ヨー角変化と制御限界相 対ヨー觕の結果を図 6 に示す。

図 6 より明らかなように, 相対ヨー角ゲインは後ろ の車兩ほど小さく, またその限界值および限界值に達 する後退距離も後ろの車両ほど小さくなることがわか る.このように, 制御限界の面からも後端車両の動き が重要となり，摆縦者に大きな負担を与えていること がわかる。

\section{6. 結 論}

本研究は多重連結車両の後退理論を導きこれを用 い可制御性，最適後退制御および制御限界を示した。

これらの結果から, 多重連結車両の後退時の操綐の 難しさは，単に自由度が增えることによるだけではな く，奏際には視覚的情報を受け取りにくい後端車両の 運動を大きく操舵にフィードバックさせる必要があ りまたこの後端車両が制御限界を超えやすいことな どが明らかとなった。しかしこの多重連結車両の場合 でも，最適制御理論などによる運転補助システムの開 発により，後退時の極めて難しい操縱操作も改善する 可能性のあることがわかった。

\section{文献}

（1）Schultz・ぼ加1名，状態関数と線形制御系(昭 45)，249， 学献社.

（2）伊藤・ほか 7 名, Proc. 2nd IPC, (1983), 311.

(3) Jindra, F., Automob. Eng., 3(1963), 96.

（4）景山・ほか1名，自動車技術会論文集，No.22（昭 56）, 43.

(5) 斉藤, Proc. of IAVSD, (1979), 443.

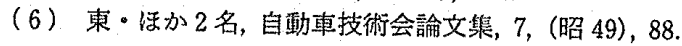

\section{討 論}

〔質問〕青木章〔(財)日本自動車研究所〕 連結車雨の操作の中で最も難しいといわれている後 退運動の理論式を導き，その計算結果と実験結果との 対比を行い,さらに多重連結車両の後退運動の可制御 性，最邀制御汸よび制御限界を明らかにされたことに 対して敬意を表す。さて，貴論文では幾何学的取扱い のできる極低速走行時の後退理論を莩いておられる が, 各種連結車両においてどのくらいの速度まで,こ の理論が適用可能かご教示願いたい。

（回答〕幾何学的取扱いの場合，各夕イヤに横す
ベりを生じないという仮定に立っている。そこで大き な求心力を要求する運動ではタイヤに横すべりを生ず るため，幾何学的な取扱いができないことになる。ま た速度の高い領域では車両の過渡運動を考毁する必要 があり，同樣に幾何学的取报いができないことにな る。しかし一般的な連結車雨の後退運動妵，高い速度 ならびに大きい楅向加速度では行われていない。そこ で本研究で示した後退運動理論が通常使用領域（後退 運動時）では十分に適用可能と考えられる。このため その適用速度限界に対卞当検討俚行っていない。 